very expressive improvement in 15 days. By the other hand, 4 animals $(28,57 \%)$ had to go on with therapy for at least one extra week. Three of them showed improvement, but, after 3 weeks of treatment, only 1 animal $(7,14 \%)$ had to be given systemic antibiotics and was considered as not responding to chlorexidine. Statistical analysis of these data by KruskalWalis non-parametric test showed a significative difference between the groups' means $(\mathrm{P}=$ $0,0422)$. Subsequently, the Dunn's multiple comparisons test revealed that such significance is expressed by differences between group 1 and group $3(\mathrm{P}<0,05)$. According to these data, it was possible to conclude that chlorexidine gluconate in $2 \%$ aqueous solution is a good choice to treat primary bacterial pododermatitis in dogs, since it showed very good results and has a very convenient and easy way of application.

\title{
30 - Onicopatia associada a vasoconstrição de arteríolas dos dígitos
}

Gonzalez,R.'; Silva, P.T.D.'; Michalany, $\mathrm{N}^{3}$
1- Clínica Médica do Hospital Veterinário da Universidade Anhembi Morumbi, São Paulo-SP

2- Departamento de Patologia da Faculdade de Medicina Veterinária e Zootecnia da Universidade de São Paulo, São Paulo-SP

3- Departamento de Patologia da Universidade Federal de São Paulo, São Paulo-SP

A vasoconstriçào das artérias dos dedos, ocorre em humanos, como forma primária na Doença de Raynaud, onde há um intenso vasoespasmo de pequenas artérias ou arteríolas locais devido ao frio ou a causas emocionais, acometendo preferencialmente mulheres jovens saudáveis. Nesta doença a resposta vasomotora local e central fisiológica torna-se exagerada levando a cianose e isquemia dos dígitos. Ou como forma secundária a Lupus Eritematoso sistêmico, esclerose sistêmica, ateroesclerose, ou a Doença de Buerger. Em cães a Doença de Raynaud foi relatada em três animais que apresentavam onicogrifose, dor intensa, e cianose em vários dedos. O presente trabalho tem como objetivo relatar este fenômeno em um cão da raça Cocker Spaniel, fêmea, 1,5 anos, atendido no serviço de Clinica Medica do Hospital Veterinário da Universidade Anhembi Morumbi com alteração de forma das unhas. Ao exame fisico, seus parâmetros encontravam-se dentro dos parâmetros da normalidade. A inspeção de suas unhas observou-se onicodistrofia, onicomadese e discreta paroniquia. Não evidenciou-se sensibilidade anormal e o animal não possuía alterações na marcha. Instituiu-se terapia anti-séptica e antibiótica com triclosan e rifamicina, respectivamente. Quinze dias após a primeira consulta, o quadro permanecia inalterado, excetuando- se ausência de paroníquia. Foram coletados fragmentos ungueais para pesquisa microbiológica e antibiograma. O resultado foi positivo para Malassezia pachydermatis. Neste momento, optouse por amputação de uma das falanges para posterior estudo histopatológico. Ao exame histopatológico evidenciou-se em córion do ápice da unha área de necrose isquêmica caracterizada por massa de colágeno amorfo entremeado a fibrócitos com núcleos picnóticos e vasos congestos com formação de vacuolização e fendas entre córion e matriz ventral e dorsal. $\mathrm{O}$ infiltrado inflamatório foi discreto e consistiu em neutrófilos e linfócitos multifocais. Não sendo evidenciados fungos, bactérias e parasitas. Quadro histológico compativel com vasoconstriçào das artérias dos dedos. Iniciou-se então o tratamento com pentoxifilina $20 \mathrm{mg} /$ BID. Trinta dias depois da instituição da terapia, observando-se menor intensidade da onicomadese. Em cães a terapia de longa duração a base de isoxsuprine, um vasodilatador, foi eficaz a dose de $1 \mathrm{mg} / \mathrm{kg} /$ dia. Dentre as onicopatias que acometem várias unhas, as mais freqüentemente relatadas são as infecções bacterianas, a leishmaniose, a ancilostomose, as doenças alérgicas, as dermatoses autoimunes, os problemas de queratinização e as genodermatoses. Acreditamos que pode-se incluir aos diagnósticos diferenciais clínico e anatomopatológico das onicopatias a vasoconstrição de artéria do dígito de causa indeterminada. 